\title{
ANALISA PEMAKAIAN BAHAN BAKAR AMPAS TEBU DAN TEMPURUNG KELAPA DENGAN MENGUJI VARIASI RASIO YANG PALING EFISIEN TERHADAP KETEL UAP SEBAGAI BAHAN BAKAR ALTERNATIF
}

\author{
Christiany N. S. ${ }^{1}$, Tekad Sitepu ${ }^{2}$, Farel H. Napitupulu ${ }^{3}$, Mahadi ${ }^{4}$, Taufiq B. N. ${ }^{5}$ \\ 1,2,3,4,5 Departemen Teknik Mesin Fakultas Teknik Universitas Sumatera Utara \\ Jalan Almamater kampus USU Medan 20155 \\ Email : christianysinaga@ymail.com
}

\begin{abstract}
Abstrak
Bahan bakar merupakan segala sesuatu yang dapat dibakar dan menghasilkan panas. Bahan bakar yang terdapat di alam dapat berupa padat, cair, dan gas. Ketel uap sangat berhubungan erat dengan bahan bakar yang digunakannya. Berdasarkan pengalaman dari penelitian yang telah dilakukan sebelumnya, bahan bakar biomassa dari limbah tanaman dapat dijadikan sebagai bahan bakar alternative yang ketersediannya dapat terus dijaga dan menghasilkan nilai kalor yang tidak kalah tinggi serta biaya yang cukup terjangkau. Salah satu pabrik yang mengaplikasikannya adalah Pabrik Gula Sei Semayang yang menggunakan ampas tebu dan fiber (cangkang dan serabut sawit) sebagai bahan bakarnya dan menghasilkan efisiensi sebesar 66\%. Tujuan penelitian ini adalah mendapatkan nilai efisiensi tertinggi dan terendah serta mendapatkan variasi rasio yang paling efisien digunakan. Penulis melakukan pengujian dan menganalisa campuran ampas tebu (AT) terhadap tempurung kelapa (TK) dengan berbagai variasi rasio menggunakan cara metode tidak langsung, yakni 90\% AT: 10\% TK, 80\% AT: 20\% TK, 70\% AT : 30\% TK, 60\% AT : 40\% TK, dan 50\% AT : 50\% TK. Dari hasil pengujian, direkomendasikan rasio bahan bakar yang paling efisien digunakan pada ketel uap merk Yoshieme Japan, dengan suhu uap $325^{\circ} \mathrm{C}$, kapasitas uap $60 \mathrm{~T} / \mathrm{jam}$, dan tekanan $29 \mathrm{~kg} / \mathrm{cm}^{2}$ adalah $90 \%$ AT : $10 \%$ TK dengan efisiensi sebesar 78,75\%.
\end{abstract}

Kata kunci : ketel uap, biomassa, rasio bahan bakar, Efisien

\section{PENDAHULUAN}

Ketel uap adalah pesawat untuk memproduksi uap pada suatu jumlah tertentu pada setiap jamnya dengan suatu tekanan dan suhu yang telah ditentukan[1]. Proses pendidihan memerlukan energi panas yang diperoleh dari sumber panas misalnya dari pembakaran bahan bakar berupa bahan bakar padat, cair dan gas. Sumber energi tak terbarukan khususnya fosil (minyak dan gas) mempunyai peran penting dalam kehidupan manusia sehari-hari. Salah satu energi terbarukan yang perlu mendapatkan perhatian untuk dikembangkan adalah energy biomassa. Energi biomassa adalah jenis bahan bakar yang dibuat dengan mengkonversi bahan biologis seperti tanaman. Dari berbagai macam tanaman, ada beberapa tanaman yang memilki kandungan biomassa tersebut, antara lain seperti tanaman sawit, jagung, kelapa, jerami, tebu, dan masih banyak lagi. Pada penulisan skripsi ini, tanaman yang akan diuji adalah tebu dan kelapa. Penggunaan energi biomassa diperoleh dari limbah tanaman itu sendiri. Limbah yang akan diuji berupa ampas tebu dan tempurung kelapa. Adapun yang menjadi alasan penulis mengangkat judul ini karena semakin sulitnya mendapatkan bahan bakar fosil yang semakin hari semakin kecil kesempatan untuk mendapatkannya, dibandingkan dengan bahan ampas tebu dan tempurung kelapa yang bisa terus menerus dihasilkan dan mudah mendapatkannya dengan harga yang terjangkau/murah. Salah satu perusahaan yang menggunakan ketel uap sebagai pembangkitnya adalah Pabrik Gula Sei Semayang di KM 12,5 Serdang Bedagai.. Pabrik ini menggunakan bahan bakar berupa Ampas Tebu dan dicampur dengan beberapa bahan bakar padat lainnya yaitu cangkang dan 
serabut kelapa sawit ditambah dengan minyak residu. Melihat potensi yang dikandung oleh kedua bahan bakar di atas, maka penulis termotivasi untuk melakukan analisa perbandingan variasi rasio bahan bakar alternatif tersebut sebagai sumber energi alternative terhadap ketel uap [2]

\section{TINJAUAN PUSTAKA}

Boiler/ketel uap merupakan bejana tertutup dimana panas pembakaran dialirkan ke air sampai terbentuk air panas atau steam berupa energi kerja. Energi kalor yang dibangkitkan dalam sistem boiler memiliki nilai tekanan, temperatur, dan laju aliran yang menentukan pemanfaatan steam yang akan digunakan. Sistem boiler terdiri dari sistem air umpan, sistem steam, dan sistem bahan bakar. Pada bagian ini, yang akan dibahas lebih lanjut adalah sistem bahan bakar. Bahan bakar (fuel) adalah segala bahan yang dapat dibakar. Berbagai jenis bahan bakar (seperti bahan bakar cair, padat, dan gas) yang tersedia tergantung pada berbagai faktor seperti biaya, ketersediaan, penyimpanan, handling, dan lain-lain. Pada penulisan ini, metode perhitungan yang digunakan adalah metode tidak langsung yaitu memperhitungkan kehilangan-kehilangan panas yang terjadi saat dilakukannya pembakaran. Berikut ini adalah rumus yang digunakan :

Tahap 1. Menghitung kebutuhan udara teoritis :

$\mathrm{Ut}=\frac{(11,43 \times \mathrm{C})+\{34,5 \times(\mathrm{H} 2-02 / 8)\}+(4,32 \times \mathrm{S})] /}{100 \frac{\mathrm{kg}}{\mathrm{kg}} \text { bahan bakar }}$

Tahap 2. Menghitung persen kelebihan udara yang dipasok

$\mathrm{EA}=\frac{\% \mathrm{O}_{2} \times 100}{21-\% \mathrm{O}_{2}}$

Tahap 3. Menghitung massa udara sebenarnya yang dipasok/kg bahan bakar

$\mathrm{ASS}=1+\left(\frac{\mathrm{EA}}{100}\right) \mathrm{x}$ udara teoritis

Tahap 4. Memperkirakan seluruh kehilangan panas :

(1) Persentase kehilangan panas yang diakibatkan oleh gas buang yang kering :

$$
\mathrm{L} 1=\frac{\mathrm{m} \times \mathrm{c}_{\mathrm{pfg}} \times\left(\mathrm{T}_{\mathrm{fg}}-\mathrm{T}_{\mathrm{a}}\right)}{\mathrm{GCV} \text { fuel }} \times 100
$$

(2) Persentase kehilangan panas karena penguapan air yang terbentuk karena adanya $\mathrm{H}_{2}$ dalam bahan bakar :

$$
\mathrm{L} 2=\frac{9 \times \mathrm{H} 2\{584+\mathrm{Cpss}(\mathrm{Tfg}-\mathrm{Ta})\}}{\text { GCV fuel }}
$$

(3) Persentase kehilangan panas karena penguapan kadar air dalam bahan bakar :

$$
\text { L3 }=\frac{M\{584+\text { Cpss (Tfg-Ta })\}}{\text { GCV fuel }}
$$

(4) Persentase kehilangan panas karena kadar air dalam udara : 
$\mathrm{L} 4=\frac{\text { AAS x kelembapan udara } \mathrm{x} \text { Cpss }(\mathrm{Tfg}-\mathrm{Ta}) \mathrm{x} 100}{\text { GCV fuel }}$

(5) Persentase kehilangan panas karena bahan bakar yang tidak terbakar dalam abu bawah/bottom ash :

L5 $=\frac{\text { Total abu terkumpul per kg b.bakar yg terbakar x GCV ba }}{\text { GCV fuel }}$

(6) Persen kehilangan panas karena radiasi dan kehilangan lain yang tidak terhitung

Persentase karena kehilangan panas karena radiasi dan konveksi serta kehilangan lain yang tidak terhitung.

Pada umumnya kehilangan panas akibat radiasi dan konveksi lebih rendah untuk boiler yang lebih besar dan lebih tinggi untuk boiler yang lebih kecil. Nilai kerugian radiasi dan konveksi biasanya ditentukan dari grafik standar American Boiler Manufactures Association (ABMA) seperti gambar di bawah ini :

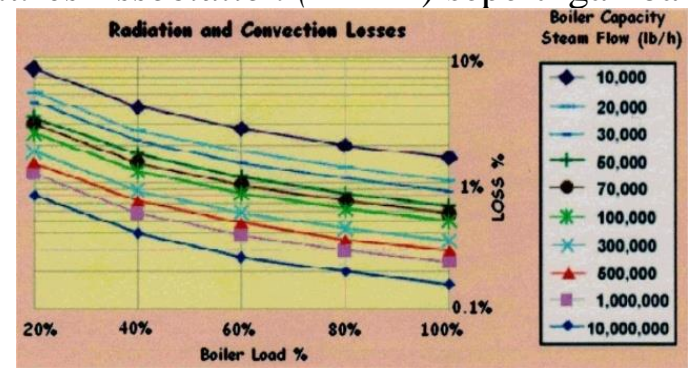

Gambar 1. Grafik yang menunjukkan kehilangan radiasi dan konveksi sesuai dengan laju aliran massa uap yang dihasilkan boiler [3].

Kapasitas uap boiler yang dimiliki adalah sebesar $60.000 \mathrm{~kg} / \mathrm{jam}$ atau $132.000 \mathrm{lb} / \mathrm{h}$ berada di antara $100.000 \mathrm{lb} / \mathrm{h}$ dan $300.000 \mathrm{lb} / \mathrm{h}$, maka untuk mendapatkan nilainya, dihitung dengan menggunakan cara interpolasi seperti pada tabel 1 berikut :

Tabel 1. Nilai akibat radiasi dan konveksi pada aliran kapasitas uap boiler

\begin{tabular}{|l|l|}
\hline $\begin{array}{l}\text { Boiler } \\
\text { capacity } \\
\text { steam flow } \\
(\text { lb/h) }\end{array}$ & $\begin{array}{l}\text { Radiation and } \\
\text { convection } \\
\text { losses }\end{array}$ \\
\hline 100.000 & 0,7 \\
\hline 132.000 & $\mathrm{X}$ \\
\hline 300.000 & 0,5 \\
\hline
\end{tabular}

$\mathrm{x}=\frac{132.000-100.000}{300.000-100.000} \times(0,5-0,7)+0,7$

$\mathrm{x} \quad=0,700 \%$

$\mathrm{L} 6=\mathrm{x}=0,700 \%$

$>$ Menghitung efisiensi boiler dan rasio penguapan boiler :

$(\mathrm{n})=100-(\mathrm{L} 1+\mathrm{L} 2+\mathrm{L} 3+\mathrm{L} 4+\mathrm{L} 5+\mathrm{L} 6)$ 
Analisa perhitungan selanjutnya setelah menggunakan metode tidak langsung adalah analisa proksimasi dan analisa nilai kalor baik itu menggunakan bom kalorimeter dan juga menggunakan rumus Dulong Petit dengan menggunakan rumus sebagai berikut :

(1) Perhitungan nilai kalor dengan bom kalorimeter :

$>$ Nilai kalor atas $(\mathrm{HHV})$

$\mathrm{HHV}=\left(\mathbf{T}_{2}-\mathbf{T}_{1}-\mathbf{T}_{\mathrm{kp}}\right) \mathrm{C}_{\mathrm{V}}(\mathrm{kJ} / \mathrm{kg})$

$>$ Nilai kalor bawah (LHV)

$\mathrm{LHV}=\mathrm{HHV}-3240 \mathrm{~kJ} / \mathrm{kg}$

Dimana :

HHV = Nilai kalor atas $(\mathrm{kJ} / \mathrm{kg})$

LHV = Nilai kalor bawah $(\mathrm{kJ} / \mathrm{kg})$

$\mathrm{CV} \quad=$ Panas jenis bom

Kalorimeter $(73529,6$

$\mathrm{kJ} / \mathrm{kg}^{\circ} \mathrm{C}$ )

Apabila dilakukan $\boldsymbol{n}$ kali pengujian, maka rumus yang digunakan adalah sebagai berikut [4]:

$$
\begin{array}{ll}
>\quad \mathrm{HHV}_{\text {Rata-rata }} & =\frac{\sum_{\mathrm{I}=1}^{\mathrm{n}} \mathrm{HHV}}{\mathrm{n}}(\mathrm{kJ} / \mathrm{kg}) \\
>\quad \mathrm{LHV}_{\text {Rata-rata }} & =\mathrm{HHV}_{\text {rata-rata }}-3240
\end{array}
$$

(2) Menggunakan rumus Dulong Petit [5]:

$>$ Nilai kalor atas (HHV) :

$$
\mathrm{HHV}=33950 \mathrm{C}+144200\left(\mathrm{H}_{2}-\frac{o_{2}}{8}+9400 \mathrm{~S}\right) \mathrm{kJ} / \mathrm{kg}
$$

$>$ Nilai kalor bawah (LHV)

$\mathrm{LHV}=\mathrm{HHV}-2411\left(\mathrm{M}+9 \mathrm{H}_{2}\right)$

Penelitian juga dilakukan dengan menganalisa perhitungan suplai udara pada proses pembakaran, analisa kebutuhan bahan bakar ketel, analisa panas yang dihasilkan di dapur, analisa volume ruang bakar, dan analisa kebutuhan bahan bakar.

\section{METODOLOGI PENELITIAN}

Metode penelitian yang dilakukan pada penulisan ini akan dijabarkan sebagai berikut :

3.1 Lokasi, jenis kegiatan, dan waktu penelitian

Penelitian ini dilakukan di tiga tempat, yaitu di laboratorium Motor Bakar Teknik Mesin USU, di laboratorium kimia FMIPA USU, dan di PT. Astra Internasional TbkToyota Medan.

\subsection{Operasionalisasi penelitian}

Operasionalisasi penelitian yang dilakukan juga terbagi menjadi dua (2) variabel antara lain :

$>$ Variabel penelitian 
Penelitian ini menggunakan tiga macam variable, yaitu variabel bebas, variabel terikat, dan variabel control. Alasan penggunaan variabel-variabel ini karena pengolahan data untuk mendapatkan efisiensi termis menggunakan metode tidak langsung.

$>$ Pengukuran variabel penelitian

Pengukuran variabel ini juga terbagi menjadi tiga (3), yaitu pengukuran variabel bebas, pengukuran variabel terikat, dan pengukuran variabel kontrol

\subsection{Instrumen penelitian}

Instrumen penelitian yang digunakan disesuaikan dengan parameter yang akan dianalisa, yaitu kadar air, kadar abu, kadar bahan mudah menguap, kadar fixed carbon,nilai kalor, dan emisi gas buang serta pengukuran berat abu hasil pembakaran bahan bakar. Instrumen yang digunakan antara lain :

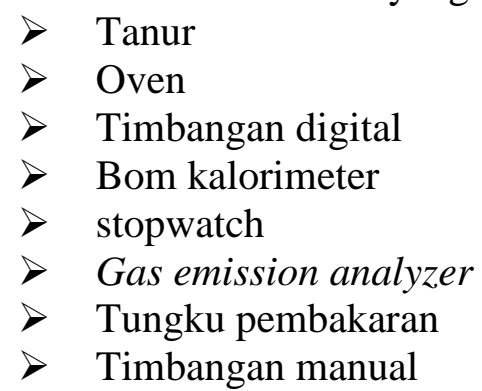

\subsection{Analisa data hasil percobaan}

Analisa data yang didapatkan dari hasil penelitian, dituangkan dalam bentuk perhitungan dengan menggunakan metode perhitungan tidak langsung seperti yang tertera pada tinjauan pustaka sebelumnya hingga akhirnya mendapatkan hasil yang diinginkan.

Percobaan untuk mendapatkan nilai beberapa parameter akan dijelaskan berikut ini. Percobaan nilai emisi gas buang dilakukan dengan mulai membakar sampel ke dalam tungku bakar sesuai dengan variasi yang ditetapkan, kemudian masukkan gas fitting emission gas analyzer ke cerobong dan ditunggu kira-kira dua menit hingga pembacaan angka hasil pengukuran di layar LED stabil. Percobaan pada nilai kalor dilakukan dengan memulai dengan mengukur berat sampel 0,15 gr dan volume air $1250 \mathrm{~mL}$ dengan tekanan oksigen 30 bar. Pengerjaan dilanjutkan dengan mengaduk air pendingin 5 (lima) menit, kemudian suhu dicatat (T1), kemudian menyalakan bahan bakar dengan bom kalori. Pengadukan dilakukan lagi selama 5 (lima) menit dan mencatat kembali suhunya (T2). Nilai HHV dan LHV dapat dihitung dengan menggunakan rumus yang tertera di tinjauan pustaka.

\section{HASIL PENELITIAN}

Hasil yang didapatkan dikaitkan dengan variasi rasio yang dipakai antara lain :

$>$ Variasi $1=90 \% \mathrm{AT}: 10 \% \mathrm{TK}$

$>$ Variasi $2=80 \% \mathrm{AT}: 20 \% \mathrm{TK}$

$>$ Variasi $3=70 \%$ AT : $30 \%$ TK

$>$ Variasi $4=60 \%$ AT : $40 \%$ TK

$>$ Variasi $5=50 \%$ AT : $50 \%$ TK 
Ampas tebu disingkat dengan (AT), dan tempurung kelapa disingkat dengan (TK). Berdasarkan hasil yang telah didapatkan pada proses pengujian dan diolah serta dianalisa dengan menggunakan perhitungan, maka didapatkan hasil penelitian sebagai berikut ini :

\subsection{Hasil perhitungan efisiensi termis}

Hasil disajikan dalam gambar 1 berikut ini :

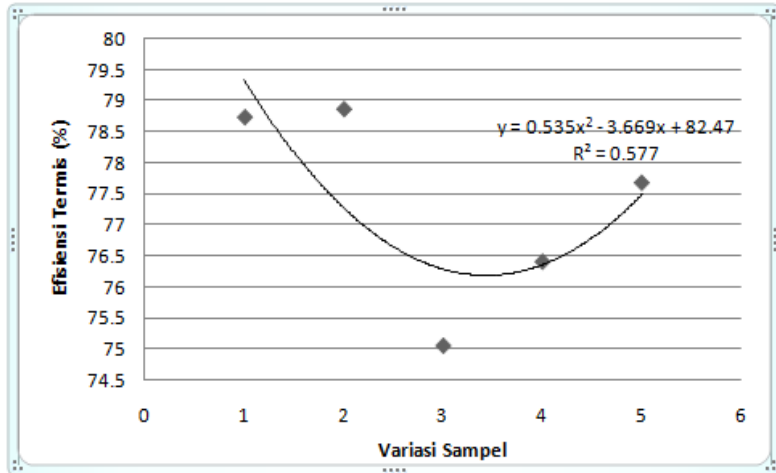

Gambar 1. Grafik hubungan variasi rasio bahan bakar terhadap efisiensi termis

Grafik di atas, terlihat bahwa setiap variasi menghasilkan efisiensi yang berbeda, dan terlihat bahwa efisiensi tertinggi ada pada variasi 2, dan efisiensi terendah pada variasi 3.

4.2 Hasil perhitungan kebutuhan bahan bakar ketel uap

Hasil disajikan dalam gambar 2 berikut ini :

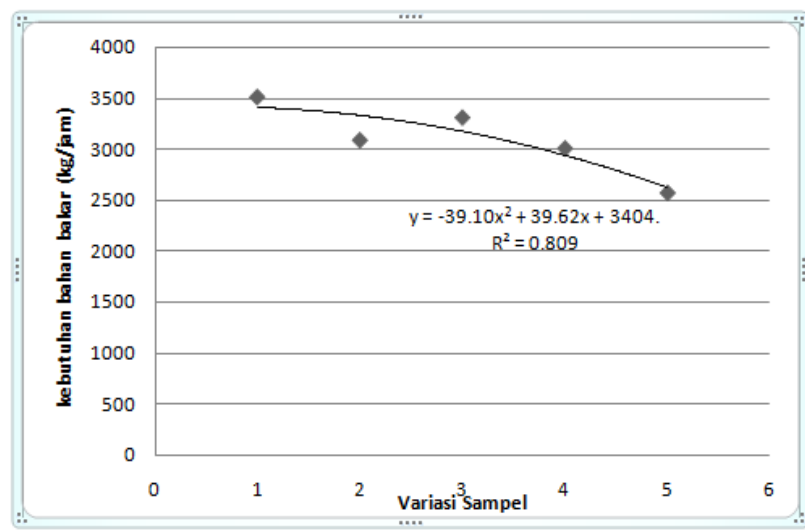

Gambar 2. Grafik hubungan antara variasi rasio bahan bakar terhadap kebutuhan bahan bakar

Pada grafik di atas terlihat bahwa variasi 2 membutuhkan bahan bakar paling sedikit, dan variasi 1 membutuhkan bahan bakar paling banyak.

4.3 Hasil perhitungan untuk panas yang dihasilkan pada dapur pembakaran

Hasil disajikan dalam gambar 3 berikut ini : 


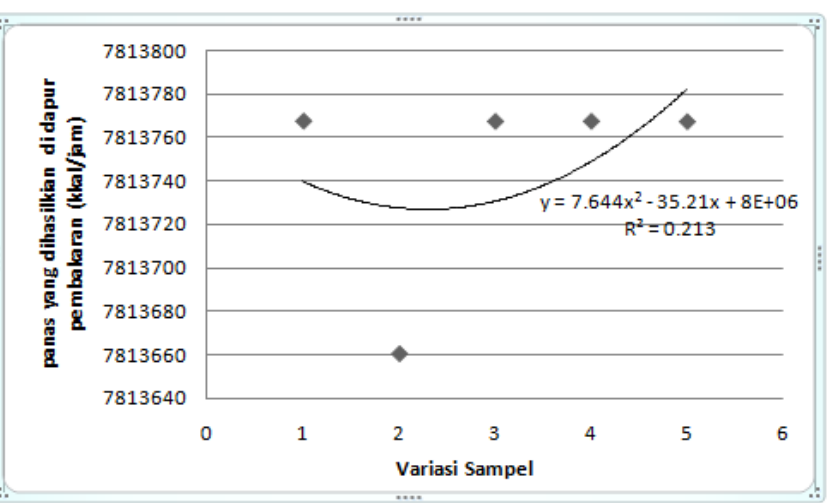

Gambar 3. Grafik hubungan antara variasi rasio terhadap panas yang dihasilkan pada dapur pembakaran

Grafik di atas menunjukkan bahwa panas yang paling sedikit dihasilkan di variasi 2,dan panas yang paling tinggi berada di variasi 1 , eskipun hanya memilki selisih panas yang sedikit dibanding variasi 3,4 , dan 5 .

4.4 Hasil perhitungan biaya yang dibutuhkan

Kebutuhan biaya pada berbagai variasi rasio ini, dihubungkan dengan besarnya bahan bakar yang digunakan. Hasil perhitungannya disajikan dalam gambar 4 berikut ini :

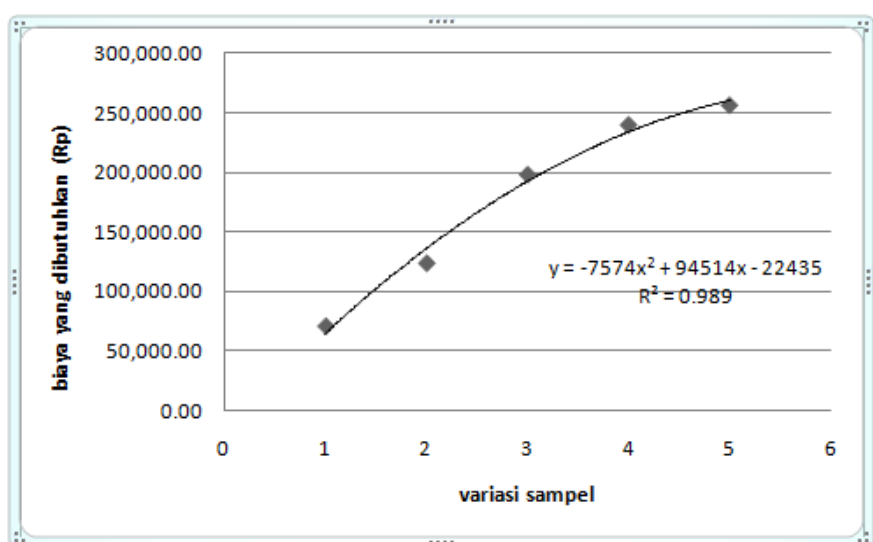

Gambar 4. Grafik hubungan antara variasi rasio terhadap biaya yang dibutuhkan

Dari grafik di atas terlihat bahwa biaya yang paling rendah dikeluarkan pada variasi 1 , dan biaya paling tinggi dikeluarkan pada variasi 5 .

\section{KESIMPULAN DAN SARAN}

Kesimpulan

(1) Efisiensi tertinggi dihasilkan pada variasi rasio 80\% AT : 20\% TK sebesar 78,88\%, dan efisiensi terendah dihasilkan pada variasi rasio 70\% AT : 30\% TK sebesar $75,05 \%$

(2) Variasi rasio yang paling efisien direkomendasikan sebagai bahan bakar alternatif untuk ketel uap merk Yoshieme Japan, dengan suhu uap $325^{\circ} \mathrm{C}$, kapasitas uap 60 $\mathrm{T} / \mathrm{jam}$, dan tekanan $29 \mathrm{~kg} / \mathrm{cm}^{2}$ adalah variasi $90 \%$ AT : 10\% TK, dengan alasan dilihat dari : 
- Nilai efisiensi yang berbeda hanya 0,13 antara variasi rasio 80\% AT : 20\% TK dengan $90 \%$ AT : $10 \%$ TK

- Panas yang dihasilkan oleh variasi 90\% AT : 10\% TK sebesar 7813767,251 $\mathrm{kkal} / \mathrm{jam}$ lebih besar dibandingkan variasi $80 \%$ AT : $20 \%$ TK sebesar 7813660,057 kkal/jam, dengan perbedaan panas sebesar 107,194 kkal/jam

- Biaya yang dibutuhkan untuk setiap pembakaran per jam pada variasi rasio $90 \%$ AT : 10\% TK sebesar Rp 70.092,124, sementara variasi rasio 80\% AT : 20\% TK sebesar Rp 123.353,284, memiliki perbedaan sebesar Rp 53.261,16

Saran

(1) Untuk meningkatkan efisiensi, sebaiknya semakin diteliti bahan bakar biomassa lain yang lebih tinggi nilai kalornya dibandingkan tempurung kelapa.

(2) Pada saat pengujian suhu dan gas emisi gas buang untuk nilai $\mathrm{O}_{2}$ dan $\mathrm{CO}_{2}$ sebaiknya dilakukan sampai lebih dari tiga kali, agar memastikan nilainya tetap sama, atau berubah-ubah, sehingga memiliki nilai yang pasti

(3) Saran dari supervisor PT. Astra International Tbk - Toyota, tempat penulis menguji emisi gas buang, agar demi perkembangan kemajuan mahasiswa, khususnya mahasiswa teknik mesin USU, agar lebih dilengkapi fasilitasnya, seperti mesin gas emission analyzer, dan alat uji lainnya.

\section{DAFTAR PUSTAKA}

[1] Hasibuan.Harry Christian dan Farel H. Napitupulu, Analisa Pemakaian Bahan dengan Melakukan Pengujian Nilai Kalor Terhadap Performansi Ketel Uap Tipe Pipa Air dengan Kapasitas Uap 60 T/jam, jurnal e-Dinamis volume 4 No. 4 Maret 2013

[2] Syamsir.A Muin, 1998, Pesawatpesawat Konversi Energi Ed. 1, Jakarta : Rajawali

[3] Hazwi. Mulfi dan Grata Patisarana, Optimalisasi Efisiensi Termis Boiler Menggunakan Serabut dan Cangkang Sawit sebagai Bahan Bakar, Jurnal Dinamis volume I No.11 Juni 2012

[4] Buku panduan praktek Bom Kalori meter laboratorium prestasi mesin FT USU

[5] Napitupulu.Farel H, Pengaruh Nilai Kalor (Heating Value) Suatu Bahan Bakar Terhadap Perencanaan Nilai Kalor Bahan Bakar yang Digunakan, jurnal Sistem Teknik Industri volume 7, No. 1 Januari 2006 